Author Accepted Version. Final version published as: Temple, J., \& Gan, L. (2020). Habits of a Lifetime: Museum Visitation Amongst Older Australians. Journal of Population Ageing, 1-19.

\title{
Habits of a Lifetime: museum visitation amongst older Australians
}

\begin{abstract}
Recent studies have shown that cultural engagement, including museum attendance, is associated with improved health and wellbeing among older people. Understanding the correlates and reasons for attending museums and art galleries in later life is therefore an important area of research. In this paper, we employ an innovative mixed methods approach to understand museum attendance among older Australians (aged 60 and over). The quantitative component of our study found that (1) the prevalence of museum attendance is substantial, with one in three Australians aged over 60 attended a museum in 2014; (2) high income, holding assets and involvement in cultural activities in childhood were all strongly associated with attendance; (3) that demographic groups less likely to attend included those aged over 80, persons born in a non-English speaking country and those reporting poor or fair health, and (4) the most prevalent reason for non-attendance was 'not interested' or 'no need'. The qualitative data from the two pilot studies confirmed the quantitative findings and provided further nuanced detail around reasons for attendance, potential strategies to encourage groups less likely to attend and how functional limitations are experienced in museum environments. These findings are important for museums and underscore the long-term and inclusive value of intergenerational programs, museum visitation as a social activity, the importance of physical comfort and ease and the potential of communication around the opportunities and benefits of museum visitation.
\end{abstract}

Keywords: Ageing, Museums, Intergenerational relationships, Mixed methods

\section{Funding and Ethics Approvals}

The Australian Research Council's (ARC) Centre of Excellence in Population Ageing Research (CE1101029).

The Hallmark Ageing Research Initiative provided seed funding for research pilot \#1.

Ethics ID: 1647455 Approval granted 26 ${ }^{\text {th }}$ August 2016.

The McCoy Seed Funding Scheme provided the grant for research pilot \#2.

Ethics ID: 1749338 Approval granted 19 $9^{\text {th }}$ June 2017. 


\section{Introduction}

As with most countries around the globe, the number of older people in Australia is increasing rapidly. By 2055 Australia's older population (65+) will double and the number aged 85 and over is projected to double in the next 25 years ${ }^{1}$. Australian governments are increasingly supporting ageing in place and active, healthy ageing in an attempt to keep people in good health for as long as possible to mitigate potential costs attributable to population ageing (EY, 2016). In this context, cultural institutions have the potential to support and foster age-friendly environments, social inclusion and age-integrated societies (Dodd, Jones, Plumb, McGhie, \& Blazejewski, 2018).

Cultural institutions such as museums, are repositioning themselves for greater relevance in rapidly evolving societies. Historically many cultural institutions were perceived as elitist and exclusive in approach. However, with changing values and increasingly older and diverse populations, the focus of cultural institutions has continued to shift from preservation, presentation and education to greater community engagement, social inclusion, and health and wellbeing (Hamblin \& Harper, 2016). These institutions are seeking to maximise the diversity and reach of their programs to demonstrate value for money especially to government, funders and other stakeholders. Museums have only recently begun to realise the potential of actively engaging with older people as consumers of culture, knowledge bearers, champions, volunteers, learners and donors (Dodd et al., 2018). In addition, bringing multigenerational and multi-cultural groups together in cultural institutions has the potential to build and strengthen communities and support and foster health and wellbeing for all citizens.

\section{Health, wellbeing, ageing and museums}

Health from the biomedical viewpoint has been conceived of in terms of the presence or absence of illness, infirmity or injury, and wellbeing as life satisfaction. In 1946, the World Health Organisation (WHO) defined health as "a state of complete physical, mental and social wellbeing and not merely the absence of disease or infirmity." (https://www.who.int/about/who-we-are/constitution). However, in recent times, health and wellbeing are increasingly being viewed as more complex, multi-dimensional and dynamic concepts. Factors such as lifestyle, social networks, and socio-economic, cultural and environmental conditions are incorporated in definitions of health and wellbeing, and there is more of a focus on resilience, capacity to cope, adapt and self-manage (Clift \& Camic, 2016; Huber et al., 2011). Using more holistic and interdisciplinary approaches to health and wellbeing, prevention becomes as important as cure and opens the door for organisations such as cultural institutions to involve themselves (Dodd \& Jones, 2014). Although in the past two decades significant public policy developments in the areas of health and social care now promote active ageing and ageing in place, there have been no

1

https://www.abs.gov.au/ausstats/abs@.nsf/mediareleasesbytitle/58FF5A2527DDD70ECA2568A90013634F?Op enDocument 
specific policies that address the impact of demographic changes in relation to the cultural sector in Australia or the UK (Clift \& Camic, 2016; Hamblin \& Harper, 2016). This lack of specific policies is an important gap that needs to be addressed.

Governments around the world now recognise that social isolation and loneliness have long-term adverse effects on health and wellbeing, such as depression (Hawkley \& Cacioppo, 2010; NolenHoeksema \& Ahrens, 2002), increased blood pressure (Steptoe, Owen, Kunz-Ebrecht, \& Brydon, 2004), risk of cardiovascular disease and risk of developing dementia (Amieva et al., 2010; Fratiglioni, Paillard-Borg, \& Winbladj, 2004; Hawkley \& Cacioppo, 2010; Owen, 2001; Steptoe et al., 2004). Not only that, but socially isolated adults are up to five times more likely to die prematurely (Marmot Review Team, 2010). Some evidence in Australia and the UK indicates that around 10\% of people over $65 y$ rs feel socially isolated and/or lonely. This is likely to be a conservative figure, as many people will not self-identify as socially isolated or lonely (Victor \& Scharf, 2005). Interventions that "promote active social contact and encourage stimulating creative activity with support and guidance from a mentor" (Greaves \& Farbus, 2006), have shown potential for positively impacting socially isolated older people's quality of life and health (Andersson, 1985; Angus, 2002; Ciechanowski et al., 2004; Greaves \& Farbus, 2006; McAuley et al., 2000). Social networks in general have also been found to be protective against dementia or cognitive decline and important to recovery following illness (Camic \& Chatterjee, 2013).

\section{Participation and cultural attendance}

A large body of research exists that indicates older people are happier, healthier and more likely to flourish if they engage in meaningful activity, are socially active and participate in life (Glass, Leon, Marottoli, \& Berkman, 1999; Luoh \& Herzog, 2002; Menec, 2003). Epidemiological research provides evidence that 'general cultural attendance' on a regular basis is associated with increased longevity, alongside beneficial impact on mental health and wellbeing (Bygren, Konlaan, \& Johansson, 1996; Cuypers, Krokstad, Lingaas Holmen, et al., 2012; Davies, Knuiman, Wright, \& Rosenberg, 2014; Konlaan et al., 2000; O'Neill, 2010; Ruiz, 2004; Staricoff, 2004; Wilkinson, Waters, Bygren, \& Tarlov, 2007). In a longitudinal study, Johannson et al found that culturally active participants had a significantly reduced risk of impaired perceived health in comparison with those who were not culturally active (Johansson, Konlaan, \& Bygren, 2001). They also found that cultural stimulation was a perishable commodity and requires regular engagement. Davies, Knuiman \& Rosenberg (2016a) found evidence that two or more hours per week of arts engagement resulted in an enhanced level of subjective mental wellbeing.

Based on the existing evidence underscoring the importance of cultural engagement to wellbeing in later life, we utilised unique nationally representative survey data to examine the attendance behaviours 
of older Australians at museums (science, history, culture, art). We sought to answer three questions. Firstly, what is the incidence of attendance at galleries and museums in later life? Secondly, what are the demographic and economic correlates of attendance? Finally, for those who do not attend museums and galleries, what are their reported reasons for non-attendance? We conclude with a summary of the utility of our findings, particularly as they relate to potential behaviours of cultural institutions to foster increased attendance and inclusion of both older and younger Australians.

\section{Methods}

To answer these research questions, our study employs a mixed-method design combining robust quantitative evidence supplemented by more nuanced qualitative data (Clift \& Camic, 2016). Specifically, data for this investigation derive from two sources: nationally representative survey data from the 2014 General Social Survey (GSS) and qualitative data from 147 respondents in two museum pilot studies undertaken in 2017. The key findings from the quantitative analysis were investigated further using insights from the qualitative data to more explicitly reveal detail around underlying behavioural motivations and drivers of museum attendance.

\section{A. Quantitative Data}

Quantitative data for this study come from the 2014 General Social Survey (GSS) conducted by the Australian Bureau of Statistics (ABS) between March and June 2014 (ABS, 2015b). Using a face-toface interview along with prompt cards, the ABS collected information using a Computer Assisted Interviewing questionnaire on a range of domains to understand the "multi-dimensional nature of relative advantage and disadvantage across the population, and to facilitate reporting on and monitoring of people's opportunities to participate fully in society" (ABS, 2015a). The GSS was designed to provide nationally and state representative estimates across these domains.

The ABS GSS included an initial sample of 18,574 private dwellings of which 16,145 dwellings were used due to issues of scope or uninhabited dwellings. In total, $80 \%$ fully responded, yielding a sample of 12,932 people aged 15 years and over. From this final sample, we only included respondents aged 60 years and over, yielding a final sample size of 3,963 respondents. Restricting the sample to Australians aged 60 and over is consistent with the cohorts examined in the qualitative pilot studies (detailed below).

GSS field operations were conducted by the ABS under the provisions of the Census and Statistics Act (CSA) 1905. Prior to field operations, the GSS instrument was submitted to the Australian Privacy Commissioner and tabled in the Australian Parliament. Confidentiality of these data are guaranteed under the Act and information was provided freely from respondents. Confidentialised data and access 
to the Remote Access Data Laboratory (RADL) were made available to the authors for this study through the ABS and Universities Australia agreement.

\section{Measurement}

Measurement of attendance at museums and art galleries was included in the attendance at cultural venues module in the ABS GSS. Respondents were asked "I would now like to ask you about various culture and leisure venues you may have been to in the last 12 months. In the last 12 months have you visited or attended any of the following?" A prompt card (Prompt card 11) was then displayed to the respondent listing "1. Public library, 2. Museum or art gallery, 3. Botanic garden, zoo or aquarium, 4. Movie theatre, 5. Concert, theatre or other performing arts event or 6. Did not visit any of these". Our dependent variable, attendance at a museum within the last 12 months is recoded zero for those not attending and one for those reporting " 2 . Museum or art gallery" from the prompt card above. Respondents who did not attend a museum in the previous 12 months were further asked "What is the main reason you did not visit or attend a Museum or art gallery?'. A prompt card (Prompt card 12) was displayed listing: "1. Cost, 2. No time, 3. Not interested/no need, 4. Not convenient, 5. No transport, 6. Health reasons, 7. Accessed over the internet, 8. Other".

In the community participation module of the ABS GSS, respondents were also asked about participation in events as a child. Respondents were asked "When you were a child, did you participate in any of the following activities?" A prompt card was displayed (Prompt card F32) with a list of 8 items, of which one included "Arts/culture related activities (such as drama, dance, music)".

The measurement of demographic factors (eg. age, sex, county of birth) in the ABS GSS is straightforward. However, a number of economic variables require explanation. The measure of household income available in these data is gross household income, adjusted or 'equivalised' using an equivalence scale to account for household size. The ABS then provides this measure collapsed into deciles for use on the confidentialised unit record file.

\section{Statistical Model}

To model the association between demographic and economic characteristics and attendance at museums, we fitted multivariable logistic regression models. Using the raw logit coefficients, we calculated odds ratios (OR) which measure the change in the odds of attendance in the previous 12 months given a change in a covariate, once all other factors in the model are controlled.

Specifically, we modelled variations in attendance as they pertain through age, gender, marital status, country of birth, self-rated health, motor vehicle access, household income, labour force status, and presence of non-housing assets. We also included a measure of engagement in cultural activities as a child as an indicator of life-long cultural engagement. Due to the complex survey design, additional 
adjustments were necessary to generate correct variance estimates. Unfortunately, the ABS does not provide information on the primary selection unit due to privacy concerns. However, the ABS provides 60 replicate weights, in addition to a person weight, to adjust for sample design and non-response. We employed the delete-one jackknife method to provide correct standard errors for the estimated logit coefficients (Winter, 2008; Wolfer, 1985). This provided an alternative to the standard Taylor series linearization methods when only replicate weights were available.

\section{B. Qualitative Data}

Two pilot studies provided the qualitative data used in this study. Pilot \#1 consisted of focus groups of 60 to 90 minutes with older visitors in each of three museums in early 2017: the Ian Potter Museum of Art, Shepparton Art Museum and the Melbourne Museum. These museums are a university, regional and large metropolitan museum respectively. Focus groups comprised six to nine local residents aged $60+$ years who visit the museum regularly. Museums recruited the 24 participants through their networks. The 10 men and 14 women were aged from mid 60s to 80s. Discussions were semi-structured and focussed on understanding the frequency and motivations for attendance; who they attended with; the physical environment; preferences regarding exhibits; and the relationship of the museum with its community. In addition, three staff members from each museum were interviewed.

Qualitative pilot \#2 was a collaborative study with and at the Melbourne Museum and comprised 103 five-minute surveys and 39 individual semi-structured interviews with visitors aged 60 years and over, with about 19 participating in both. Potential participants were identified when using their Seniors Card (available to those aged 60+ years) for free entry and recruited by researchers during August and October 2017. The purposeful sample aimed at diversity rather than population representation. The goal of the semi-structured interviews was to gain a deeper understanding of the motivations, barriers, benefits, perceptions, habits and potential incentives that might encourage increased visitation. Ages ranged from $60-85$ years and were evenly divided in terms of gender. The sample comprised 15 who lived in Victoria, 10 from interstate and 13 international visitors.

Ethics approval for these two projects was granted by the University of Melbourne Faculty of Arts Human Ethics Advisory Group in 2016 for Pilot \#1 Ethics ID 1647455 and in 2017 for Pilot \#2 Ethics ID 1749338 respectively.

\section{Results}

\section{A. Quantitative Results}

In this section, we discuss results from the analyses of the 2014 GSS, before contextualising our findings with the qualitative results from the pilot studies detailed above. Table 1 displays the percentage of persons aged 60 and over attending art galleries or museums during 2014, disaggregated by a range of 
demographic and economic characteristics. At the population level, just over one in three older Australians attended galleries or museums (35.1\%). Of the demographic characteristics, attendance declined with age (21.8\% for those aged $80+$ compared with $40 \%$ of those aged $60-69)$, was lower among those born in non-English speaking countries (19.5\% versus 38\% of the Australian born) and was significantly higher for those with a university education $(57.2 \%$ versus $31 \%$ of those with no university education). Females were only slightly more likely to report attendance (36.9\% versus $33.2 \%)$.

Of the economic factors, attendance varied considerably by household income, labour force status and asset status. Almost $60 \%$ of persons in the top $20 \%$ of the income distribution attended a museum or gallery compared with about one quarter of those in the lowest $20 \%$ of income. Given this strong income effect, it is not surprising then that those holding consumer assets were about twice as likely to attend a gallery relative to those with no assets. Perhaps reflective of an age effect, less than one in three of those not in the labour force attended compared with almost half of the employed (45.3\%).

Apart from varying with demographic and economic characteristics, strong differences in attendance appears by whether the respondent participated in the arts and other cultural activities as a child. About half of those who were involved with cultural activities as a child, attended art galleries or museums as an adult, compared to just over one quarter of those who were not involved in these activities during childhood. Reporting good self-rated health (as opposed to poor or fair health) and access to a motor vehicle was strongly associated with attendance. 
TABLE 1: Percentage of older Australians attending a museum by demographic and economic characteristics, 2014

\begin{tabular}{|c|c|c|c|c|}
\hline & & $\mathbf{n}=$ & $\%$ attending museum & \\
\hline \multicolumn{5}{|l|}{ Age } \\
\hline & $60-69$ & 1957 & 39.9 & \\
\hline & $70-79$ & 1286 & 34.3 & \\
\hline & $80+$ & 720 & 21.8 & \\
\hline \multicolumn{5}{|l|}{ Gender } \\
\hline & Male & 1721 & 33.2 & \\
\hline & Female & 2242 & 36.9 & $* * *$ \\
\hline \multicolumn{5}{|c|}{ Marital Status } \\
\hline & Married & 1907 & 36.1 & \\
\hline & Never Married/Divorced/Separated & 1119 & 38.2 & \\
\hline & Widowed & 937 & 27.7 & $* * *$ \\
\hline \multicolumn{5}{|c|}{ Country of birth } \\
\hline & Australia & 2677 & 38.4 & \\
\hline & Main English-Speaking Country & 597 & 43.2 & $* *$ \\
\hline & Other & 159 & 19.7 & $* * *$ \\
\hline \multicolumn{5}{|c|}{ Good/Excellent Health } \\
\hline & Yes & 2785 & 40.3 & \\
\hline & No & 1178 & 21 & $* * *$ \\
\hline \multicolumn{5}{|c|}{ Access to Motor Vehicle } \\
\hline & No & 775 & 18.8 & \\
\hline & Yes & 3188 & 38.3 & \\
\hline \multicolumn{5}{|c|}{ Household Income (\% Distribution) } \\
\hline & $80-100$ & 1149 & 23.2 & - \\
\hline & $60-80$ & 1007 & 28.9 & $* * *$ \\
\hline & $40-60$ & 499 & 40.1 & $* * *$ \\
\hline & $20-40$ & 315 & 43.7 & $* * *$ \\
\hline & $0-20$ & 246 & 59.6 & $* * *$ \\
\hline & Unknown & 747 & 39.3 & $* * *$ \\
\hline \multicolumn{5}{|c|}{ Labour Force Status } \\
\hline & Employed & 914 & 45.3 & \\
\hline & Unemployed & 21 & 59 & \\
\hline & Not in the Labour Force & 3028 & 31.2 & $* * *$ \\
\hline \multicolumn{5}{|c|}{ University Education } \\
\hline & No & 3369 & 30.9 & - \\
\hline & Yes & 594 & 57.2 & $* * *$ \\
\hline \multicolumn{5}{|l|}{ Assets } \\
\hline & No & 741 & 20 & - \\
\hline & Yes & 3111 & 38.2 & $* * *$ \\
\hline \multicolumn{5}{|c|}{ Attendance as a Child } \\
\hline & No & 2687 & 28.1 & - \\
\hline
\end{tabular}




\begin{tabular}{|l|l|l|l|l|}
\hline & Yes & 1276 & 49.1 & $* * *$ \\
\hline & & & \\
\hline All 60+ & 3963 & 35.1 & \\
\hline
\end{tabular}

These bivariate results combined, shows considerable variation in attendance by demographic and economic characteristics. However, these results may be due to the confounding effect of health status. For example, attendance at a museum of gallery may decline with age due to declining health. A further question relates to the different life course histories between men and women in this cohort of older Australians. Are the demographic and economic characteristics explaining attendance differently for females compared to males?

Results in Table 2 present odds ratios from three multivariable logistic regression models with adjustments made for complex survey design. Model 1 reports the odds ratios (OR) measuring the association between each independent variable and the odds of attendance at museums and art galleries for the full population aged 60 and over. Models 2 (males) and 3 (females) stratify this analysis by gender. In interpreting the regression results below, it is important to recognise that as the GSS is a cross-sectional dataset, we are observing associations between socio-demographic characteristics and museum attendance, rather than drawing causal inferences.

Confirming results from the bivariate analyses, when controls for all other factors in the model are included, demographic groups less likely to attend art galleries and museums included those aged 80 and over $(\mathrm{OR}=0.55 \mathrm{p}<0.01)$, persons born in a non-English speaking country $(\mathrm{OR}=0.41 \mathrm{p}<0.01)$ and those reporting poor or fair health $(\mathrm{OR}=0.57 \mathrm{p}<0.01)$. Of the economic factors, high income and holding assets was also strongly associated with attendance $(\mathrm{p}<0.01)$. Holding a university education $(\mathrm{OR}=2.36$ $\mathrm{p}<0.001)$ or involvement in cultural activities or the arts as a child $(\mathrm{OR}=2.17 \mathrm{p}<0.001)$ more than doubled the likelihood of attendance, independent of other socio-economic factors included in the model. Neither marital status or gender was significantly associated with attendance $(\mathrm{p}>0.1)$.

Although gender was not significant, it is plausible that due to differential life course histories in this current cohort of older Australians (e.g., large gender differences in labour force participation reflective of the male breadwinner model in Australia's past), that factors associated with attendance may differ by gender.

There is a great deal of stability in direction and significance of parameter coefficients across the stratified male (model 2) and female (model 3) models. Confirming earlier results, in both populations, attendance at museums decreases after 80 years of age, is lower among Australians born in non-English 
speaking countries and for those reporting poor self-assessed health. Marital status was not significant in either model, indicating no marital premium in attendance at art galleries and museums.

However, results in Table 3 display some interesting differences in factors associated with attendance between males and females. For females, household income is strongly associated with attendance throughout the full income distribution, whereas for males, only low income (in the bottom $20^{\text {th }}$ percentile) explains lower attendance. For males, the association of childhood attendance with attendance in later life is very strong $(\mathrm{OR}=2.85, \mathrm{p}<01)$. Although strongly significant for females, the effect is somewhat reduced $(\mathrm{OR}=1.77 \mathrm{p}<0.01)$. In contrast, holding a university education appears to be more strongly associated with attendance for females $(\mathrm{OR}=3.44 \mathrm{p}<0.01)$ relative to males $(\mathrm{OR}=1.68$ $\mathrm{p}<0.05)$.

TABLE 2: Logistic regression models of attendance at museums, 2014

\begin{tabular}{|c|c|c|c|c|c|c|c|c|}
\hline & & Model & & & Model 2 & & Model 3 & \\
\hline & & Males & males & & Males & & Females & \\
\hline & & $\begin{array}{l}\text { Odds } \\
\text { Ratio } \\
\text { (OR) }\end{array}$ & $95 \% \mathrm{CI}$ & & $\begin{array}{l}\text { Odds Ratio } \\
\text { (OR) }\end{array}$ & & $\begin{array}{l}\text { Odds Ratio } \\
\text { (OR) }\end{array}$ & \\
\hline Age & & & & & & & & \\
\hline & $60-69$ & - & & & & & & \\
\hline & $70-79$ & 0.93 & $0.70,1.23$ & & 1.04 & & 0.81 & \\
\hline & $80+$ & 0.55 & $0.37,0.83$ & $* * *$ & 0.59 & $*$ & 0.54 & $*$ \\
\hline Gende & & & & & & & & \\
\hline & Male & - & & & n.a. & & n.a. & \\
\hline & Female & 1.21 & $0.89,1.64$ & & n.a. & & n.a. & \\
\hline Marit & l Status & & & & & & & \\
\hline & Married & 1.03 & $0.77,1.39$ & & 0.93 & & 1.15 & \\
\hline & $\begin{array}{l}\text { Never Married/ } \\
\text { Divorced/ } \\
\text { Separated }\end{array}$ & 0.9 & $0.62,1.30$ & & 0.79 & & 0.99 & \\
\hline & Widowed & & & & & & & \\
\hline Count & ry of birth & & & & & & & \\
\hline & Australia & - & & & & & & \\
\hline & $\begin{array}{l}\text { Main English- } \\
\text { Speaking Country }\end{array}$ & 1.13 & $0.78,1,64$ & & 1.24 & & 1.04 & \\
\hline & Other & 0.41 & $0.29,0.58$ & $* * *$ & 0.5 & $* *$ & 0.34 & $* * *$ \\
\hline Good/ & Excellent Health & & & & & & & \\
\hline & Yes & - & & & & & & \\
\hline & No & 0.57 & $0.44,0.73$ & $* * *$ & 0.56 & $* * *$ & 0.56 & $* * *$ \\
\hline Access & to Motor Vehicle & & & & & & & \\
\hline & No & - & & & & & & \\
\hline
\end{tabular}




\begin{tabular}{|c|c|c|c|c|c|c|c|c|}
\hline & Yes & 1.51 & $1.07,2.13$ & $* *$ & 1.14 & & 1.76 & $* *$ \\
\hline \multicolumn{9}{|c|}{ Household Income (\% Distribution) } \\
\hline & $80-100$ & - & & & & & & \\
\hline & $60-80$ & 0.63 & $0.32,1.23$ & & 0.85 & & 0.32 & $* *$ \\
\hline & $40-60$ & 0.62 & $0.33,1.18$ & & 0.85 & & 0.31 & $* *$ \\
\hline & $20-40$ & 0.46 & $0.27,0.80$ & $* * *$ & 0.51 & & 0.28 & $* * *$ \\
\hline & $0-20$ & 0.41 & $0.22,0.76$ & $* * *$ & 0.48 & $*$ & 0.24 & $* * *$ \\
\hline & Unknown & 0.67 & $0.39,1.20$ & & 0.89 & & 0.36 & $* *$ \\
\hline \multicolumn{9}{|c|}{ University Education } \\
\hline & No & - & & & & & & \\
\hline & Yes & 2.36 & $1.72,3.25$ & $* * *$ & 1.68 & * & 3.44 & $* * *$ \\
\hline \multicolumn{9}{|c|}{ Assets } \\
\hline & No & - & & & & & & \\
\hline & Yes & 1.8 & $1.30,2.50$ & $* * *$ & 1.82 & $* *$ & 1.81 & $* *$ \\
\hline \multicolumn{9}{|c|}{ Attendance as a Child } \\
\hline & No & - & & & & & & \\
\hline & Yes & 2.17 & $1.65,2.87$ & $* * *$ & 2.85 & $* * *$ & 1.77 & $* * *$ \\
\hline
\end{tabular}

For those who did not attend a museum, the ABS GSS enables an examination of the self-reported reasons for not doing so. Just over one half of non-attending respondents simply reported "not interested' or 'no need'. Around 10\% reported 'not convenient', 'health reasons' or 'no time'. Very few reported difficulties with cost or transport.

TABLE 3: Reasons for NOT attending museums, 2014

\begin{tabular}{|l|r|r|}
\hline Barrier & $\mathbf{n}=$ & \% reporting barrier \\
\hline Not interested/no need & 1384 & 51.2 \\
\hline No time & 291 & 14 \\
\hline Health reasons & 359 & 12.7 \\
\hline Not convenient & 263 & 11 \\
\hline Otherf & 162 & 6.7 \\
\hline Cost & 70 & 2.4 \\
\hline No transport & 73 & 2.2 \\
\hline TOTAL & $\mathbf{2 , 6 0 2}$ & $\mathbf{1 0 0}$ \\
\hline
\end{tabular}

$\mathrm{x}$ Includes accessing information on the internet as an alternative to visiting, and other reasons.

\section{B. Qualitative Results}

Participant discussions from pilot \#1 focussed on: the physical environment; community connection; museum disposition; exhibitions, displays and activities; social aspects; and visit motivations. The six emergent themes from Pilot \#2 were that museums are places: of learning and stimulation; of enjoyment, engagement and entertainment; for seeing; of social inclusion; for intergenerational 
experiences; and for uplifting experiences. These themes were arrived at through inductive analysis wherein interview responses were coded manually and analysed thematically. The analysis involved four key steps for an iterative process of thematic analysis: initial analysis to develop a preliminary set of descriptive codes; grouping into four main topic areas with categories for each topic; identification of six emergent themes; and expert input and interpretation from the multi-disciplinary advisory group.

\section{Discussion: Qualitative reflections on the quantitative findings}

The quantitative analysis uncovered four key findings, namely:

- The prevalence of attendance at museums and galleries by older Australians is considerable, with approximately one third of respondents attending in 2014;

- Involvement in arts and cultural activities as a child was strongly associated with museum and gallery attendance in later life;

- Attendance was lower for several groups including those born in non-English speaking countries, those in self-reported poor or fair health and those without access to a car, and

- For those not attending a museum or art gallery, the strongest barrier was lack of interest or need

In this section, we examine these findings in further detail in the light of the qualitative data from the two pilot studies.

\section{(1) Prevalence of Attendance}

The quantitative data show that just over one third of Australians aged over 60 years, attended a museum or gallery in 2014. In the context of population ageing, the increase in this population presents a unique opportunity for cultural institutions. The GSS did not ask for visitation reasons or frequency, however the qualitative data provides rich information in this area. Participants in pilot \#1 cited the social aspect of museums as one of the main reasons for visiting museums. They also cited other reasons such as special exhibitions of interest; access to stories, information, something new, history, adventure and different cultures; along with wanting to be challenged, stimulated, inspired, uplifted and impelled to reflect and learn.

The social aspect of the museum was highly significant for participants in both pilots and this manifested in the fact that well over $90 \%$ visited with a friend, partner, group or family member/s and viewed the visit as a social outing. The museum content provided stories, information, objects and curiosities to share and as catalysts for social connection, interaction and discussion. 
"They tend to come in pairs or in organised groups like U3A." P1-MJ3 Staff

"It's a good meeting place for like-minded people with similar interests." P1-SFG.

"I think it's been really good to be here in a group and have conversations with other people." PI-

$I F G$

In a critical literature review on social and leisure activity and wellbeing in later life, Betts-Adams et al (2011) found that it was social activity over physical or unspecified leisure activity that had the strongest correlation with positive wellbeing. They propose furthermore that choice and control; satisfaction; and purpose or meaning of the activity, are mediating factors. Museum visitation as a social activity potentially involves all three of these factors along with a beneficial physical exercise component.

"Great to share the experience with friends or family." P1- PFG

"I come for an art fix. I love beautiful things. Lovely pieces of art resonate, uplift and energise." P1-

SFG

"It's about browsing and discovering." $\mathrm{P} 1-\mathrm{MFG}$

Respondents also cited more abstract notions of belonging and learning as reasons for attending museums and galleries. Indeed, narratives or stories are fundamental human strategies that allow us to make sense of the world and our lives (Kenyon \& Randall, 2001). Museums are places rich in stories and stories open windows to other worlds, facilitating personal journeys of exploration (Hughes, 2016).

"The story behind an exhibition adds another level of interest rather than just the typical label. It helps people engage." $\mathrm{P} 1-\mathrm{SFG}$

"Stories are really important - it's an added dimension and increases your enjoyment." P1-PFG

"I'm visiting with a friend... we are determined to get out of our bubbles and experience the rest of the world." $\mathrm{P} 2-31 \mathrm{M}$

For participants of pilot $\# 2$, the most cited reason for visiting the museum on the day, was to bring grandchildren. Around one third of those interviewed were at the museum with grandchildren. A number of these were in multi-generational groups. Although participants in pilot \#1 didn't explicitly mention grandchildren, staff members interviewed across the three museums in pilot \#1 remarked on it. Visiting with grandchildren was not only stimulating for older people but provided a valuable sense of purpose as they facilitated the introduction of their grandchildren to the museum and contributed to their education. This aspect fulfils the potential of museums to provide spaces and conditions for "goodquality parenting and family-building", one of the recommendations of the Review of Social Determinants and the Health Divide in the WHO European Region (UCL \& WHO, 2014), and for intergenerational interaction.

"We get young children with grandparents in the summer holidays." P1-PJ3 Staff

"Coming here today was to bring my granddaughter into the museum." $\mathrm{P} 2-17 \mathrm{M}$ 
"You see grandparents encouraging the children in their pursuits..." P1-MA1 Staff

Our findings here are consistent with Whitehouse's (2015) view that intergenerational and life-long learning are central to the museum's utility for society:

"I often think of museums as some of the most intergenerational learning environments that our communities currently possess. Grandparents and grandchildren with or without parents visiting a museum are commons sights. They may be taking in the ambience and building relationships with each other, rather than paying much attention to the exhibits. Museums are as much about building human connections as they are about relationships between people and the things they produce."(Whitehouse, 2015).

Across the two pilots, average visitation frequency varied greatly from once a year to weekly. The average was four to six times annually. This is significant if we recall that the benefits of cultural engagement are perishable - just like exercise, it needs to be regular.

"I go to museums all the time and I belong to several..." $\mathrm{P} 2-30 \mathrm{~F}$

"I come weekly, to meet friends, look at art, bring visitors or just to have a break." P1-SFG

(2.) Involvement in arts and cultural activities as a child was strongly associated with museum and gallery attendance in later life, particularly for males

This finding from the GSS was strongly confirmed by the qualitative data, as well as earlier studies. A Norwegian study of over 50,000 adults found that cultural attendance and participation were associated with good health, life satisfaction and low anxiety and depression scores in general. What is interesting for museums is that for men in particular, cultural attendance rather than participation had a stronger association with positive outcomes (Cuypers, Krokstad, Lingaas-Holmen, et al., 2012).

"It's just a habit, going to museums when on vacation." $\mathrm{P} 2-12 \mathrm{M}$

"It is something (the Museum of Science \& Industry, Chicago) I loved as a child." P2-21M

This has significant implications for museums in terms of encouraging early visitation either with family members or through schools. Over the decades, what has changed is that in the past it was mostly parents who would introduce their children to museum visiting. However, in more recent times with the trend for both parents to be working, the role of introducing young children to the museum is oftentimes being filled by grandparents.

(3). Attendance was lower for a number of groups including those born in non-English speaking countries, those in self-reported poor or fair health and those without access to a car 
Museum staff interviewed in pilot \#1 indicated that the most common target markets were families, schools and a general audience. Participants and staff at one museum in pilot \#1 acknowledged that Culturally and Linguistically Diverse (CALD) communities didn't feel represented at their museum and that given their community is highly multicultural, this seemed to be a glaring omission. Suggestions regarding the inclusion of CALD community members included incorporating culturally themed content and consulting with relevant local CALD communities with a view to including personal stories and ensuring that cultural protocols were respected.

"Our market is generally white middle-class Anglo-Saxons." P1-SF2 Staff

"It would be good to include people with multicultural backgrounds; Shepparton is very multicultural." P1-SFG

With age, often come health conditions that need consideration by cultural institutions seeking to improve attendance. In both pilot studies, participants acknowledged an array of functional limitations, including hearing, vision and cognitive impairments, mobility issues, need for a wheelchair, spatial disorders and chronic back conditions. One couple both had spatial disorders, vertigo and ataxia and the wife also had a mobility issue. Large open spaces and suspended passageways were very stressful for them (P2-14M). A number of other participants spoke of the need for wheelchairs, one couple even arriving early to ensure that they could access one of the museum's wheelchairs (P2-4M). Another couple emphasised the importance for older people of facilities such as escalators and lifts being in working order (P2-27F). And a vision impaired woman in pilot \#2 related the following anecdote:

"We went to a Roman artefact museum in England. A gentleman realised I was vision impaired and he said wait a minute, wandered off and came back with a briefcase that was full of artefacts that weren't on display. Basically, they couldn't be touched, and I was touching things that were so old and I thought 'it doesn't matter what sort of museum it is there will always be someone who will go out of their way to help you have a good experience... It was amazing." (P2-6F).

In response to the call for museums to become more inclusive of people with health conditions and in advanced old age, a number of museums have outreach programs. An example is a six-week program that saw museum artifacts, images and texts taken to two aged care centres and one retirement village in Massachusetts. Participants were highly enthusiastic about seeing museum artifacts at close range; were absorbed as a group during the weekly sessions; and developed rapport quickly and easily (Sharpe \& Miller, 2015).

The ABS GSS pointed out that those with access to a car were $50 \%$ more likely to attend and that car access is highly significant for women and less so for men (Table 2). Qualitative participants cited difficulties with access to convenient public transport, parking, traffic and time spent in transit. One 
suggestion was for a short-term drop-off zone at the entrance to museums. Other comments focussed on comfort and convenience which link back to age-related health conditions discussed previously.

"I never expect museums to be comfortable." $\mathrm{P} 2-8 \mathrm{M}$

"Important qualities in museums are physical comfort, ease of movement..." $\mathrm{P} 2-9 \mathrm{M}$

Not directly linked to health, but to general comfort, one of the most common comments from all participants including staff, was the need for more, and more appropriate seating in museums. This request for more seating from museum visitors of all ages has gone unaddressed for well over a century. Well-known museum historian Kenneth Hudson predicted in 1999 that the museums which would survive in the $21^{\text {st }}$ century would be "the museums with charm and the museums with chairs." (Hudson, 1975). And as one staff member said, "Everyone gets museum fatigue" (P1-SA1). Participants also pointed out that "Low benches are not good for older people - you need backs \& arms" (P1-PFG). Commenting on the location of comfortable upholstered sofas in the first room of the Kunsthistorisches Museum in Vienna, Kenneth Hudson states that "It is, incidentally, a stroke of genius to provide such luxurious seats in Room 1. In Room 20, where exhaustion could reasonably be setting in, one might have perhaps expected them and been grateful for them, but to have them in Room 1 suggests that the visit can be undertaken at an easy pace and that, with luck, weariness need never set in at all" (Hudson, 1975).

Seating provides more than just a place to rest or take a break, it also allows visitors a moment to contemplate, reflect on and take time to understand an artefact or artwork. "There could be more seating. Sometimes it would be nice to sit down and contemplate an artefact or artwork. Seating is very important." P1-MFG. If we take the view that health and wellbeing are about adaptation, resilience and capacity to cope, and that art or artefacts are symbolic communications, then to benefit from their capacity to help us understand and create meaning from difficult or puzzling life experiences, we need to allow time and space for contemplation and reflection (Belfiore, 2016).

"More seats generally would be good so that oldies can have a sit down and take time to understand things." P2-19F

(4.) For those not attending a museum or art gallery, the strongest barrier was lack of interest or need

The quantitative analyses showed that over half of those not attending reported no interest or need. It is possible that a number of non-attendees have either never visited a museum or have an outdated perception of them as dusty, claustrophobic, patronising, old-fashioned places full of glass cabinets and unreadable labels. Yet the modern museum is a far cry from those of the period when the current $60+$ year old cohort were children. Museums today are in a continuous process of change, responding to the demands of their visitors, communities, government, and society in general. Museums have the 
potential to be enriching and transformative and visitors come in many roles and often a combination of roles. Some of those identified through the two pilot studies include: individual, grandparent, spouse, partner, friend, educator, employee, volunteer, carer, knowledge custodian, subject matter expert, champion, consumer of culture, learner and citizen. This finding suggests that museums could be communicating more effectively with potential audiences about the diverse and evolving array of artefacts, information and experiences they have to offer.

Although the ABS GSS didn't find transport as a generic category to be a strong reason for lack of attendance amongst those who hadn't attended a museum within the past 12 months (Table 3), it is generally considered to be one of the major issues that older people have in terms of social participation (Cass, Shove, \& Urry, 2005; Davey, 2007; Schwanen et al., 2015). Museum visitation is no exception. The total ABS GSS data set reflects this, showing that access to a car is a significant factor, and more so for women who were $50 \%$ less likely to attend without access.

\section{Limitations}

In interpreting results from this study, it is important to recognise the limitations. Firstly, data from the ABS GSS are cross sectional and we cannot and do not imply causation between, for example, involvement in cultural activities as a child and current attendance. Second, the ABS GSS includes persons living in private dwellings only and omits respondents from non-private dwellings such as nursing homes and hospitals. Further data collections would be necessary to generalise our findings to these populations. Finally, the ABS GSS does not provide reasons motivating attendance at a museum and does not include measures specific to the cultural institution attended. Fortunately, these latter limitations are a strength of the qualitative component of our project and points to the usefulness of mixed methods research where participant narratives can uncover significant details that might be missed by quantitative methods alone.

Nonetheless, there are a number of limitations concerning the qualitative analyses that should also be noted. These pilots included older museum visitors, but not those who did not attend. Focus groups in Pilot \#1 were small in number and participants were regular local museum visitors recruited by each museum, so likely to be well disposed towards their museums. Participants in Pilot $\# 2$ were recruited on selected days, so were a mix of local, interstate and international visitors with a preponderance of non-locals. They were asked to participate in a 20-minute semi-structured interview after their visit, so only those without time limitations and/or who were accompanied by others willing to wait, could participate. Only five of the 39 interviewees were visiting alone. 


\section{Conclusion}

Our study indicates that museums and their older visitors still have a lot to learn about each other. The quantitative component of our study showed: (1.) approximately one third of people aged $60+$ years visited museums and galleries in 2014; (2.) that involvement in cultural activities in childhood was strongly associated with attendance in later life; (3.) there was low attendance amongst those born in non-English speaking countries, those with poor to fair health and those with no access to a car; and (4.) the main barriers to attendance are lack of interest or perceived need. These results, when interpreted alongside the two qualitative data sets showed a high degree of alignment and complementarity.

A number of valuable opportunities for museums were uncovered in the qualitative data. In particular, the strongly indicated habit-forming potential of early life course attendance points to the long-term value of intergenerational programs and the encouragement of visitation amongst the older cohort who might then benefit from positive health and wellbeing outcomes. It also indicates the potential value of a life course approach to health and wellbeing research in general. Older men are notoriously difficult to engage in later life, yet for them, cultural attendance rather than participation is more strongly associated with positive outcomes and the role of grandfather appears to be a strong motivator. Intergenerational programs within cultural institutions by definition, also provide conditions for goodquality parenting, family and community-building. Museum visitation is largely considered a social activity, so providing more opportunities for social interaction, sharing and connection could enhance the museum experience. And physical comfort and ease are particularly important to older visitors as is the idea that museums should be places that encourage visitors to linger, reflect and contemplate. Participants felt that museums as public institutions should be vibrant, dynamic, engaging, comfortable, friendly and welcoming to all including those with disabilities, both visible and invisible.

These findings also have the potential to assist museums to increase the frequency of visitation. Indeed, shifts in Australia's future demography may support the aims of museums and galleries to increase attendance. Future cohorts of older Australians are projected to hold higher levels of education (Productivity Commission, 2005), to live longer (Booth and Tickle, 2003) and for many, with higher levels of income and wealth relative to previous generations (Temple et al., 2017a; Temple et al, 2017b). These changes are all positive for improving attendance among older Australians. And in fact, museum visitation in the 65-74-year-old cohort increased by 10\% from 2006 to 2014 and this trend is predicted to continue (ABS 2007, 2015). From the discussion, one could reasonably ask whether museums are currently leveraging their full potential and whether the community in general has a good understanding both of the enriching and transformative potential and the health and wellbeing benefits of museum visitation. Future research might seek to understand how museums could better communicate with older visitors and their families to encourage and support visitation. 


\section{References}

ABS. (2015a). General Social Survey: Summary Results, Australia 2014 (Cat.No. 4159.0). Canberra.

ABS. (2015b). Microdata: General Social Survey, Australia, 2014. ABS Cat.No. 4159.0.30.004.

Canberra.

Amieva, H., Stoykova, R., Matharan, F., Helmer, C., Antonucci, T., \& Dartigues, J. (2010). What aspects of social network are protective for dementia? Psychosomatic Medicine, 72(9), 905911.

Andersson, L. (1985). Intervention against loneliness in a group of elderly women: an impact evaluation. Social Science \& Medicine, 20(4), 355-364.

Angus, J. (2002). A Review of Evaluation in Community-based Art for Health Activity in the UK. London, UK: Health Development Agency.

Belfiore, E. (2016). The arts and healing: the power of an idea. In S. Clift \& P. Camic (Eds.), Oxford Handbook of Creative Arts, Health, and Wellbeing (pp. 11-17). Oxford, UK: Oxford University Press.

Bygren, L. O., Konlaan, B. B., \& Johansson, S.-E. (1996). Attendance At Cultural Events, Reading Books Or Periodicals, And Making Music Or Singing In A Choir As Determinants For Survival: Swedish Interview Survey Of Living Conditions. The BMJ, 1577-1580.

Booth, H and Tickle, L. (2004). The future aged: new projections of Australia's elderly population. Australasian Journal on Ageing, 22(4), 196-202.

Camic, P. M., \& Chatterjee, H. J. (2013). Museums and art galleries as partners for public health interventions. Perspect Public Health, 133(1), 66-71. doi:10.1177/1757913912468523

Cass, N., Shove, E., \& Urry, J. (2005). Social exclusion, mobility and access. The Sociological Review, 53, 539-555.

Ciechanowski, P., Wagner, E., Schmaling, K., Schwartz, S., Williams, B., Kulzer, J., . . James, L. (2004). Community-integrated home-based depression treatment in older adults. JAMA, The Journal of the American Medical Association(13), 1569.

Clift, S., \& Camic, P. (2016). Introduction to the field of creative arts, wellbeing, and health: achievements and current challenges. In S. Clift \& P. Camic (Eds.), Oxford Textbook of Creative Arts, Health, and Wellbeing (pp. 3-17). Oxford, UK: Oxford University Press.

Cuypers, K., Krokstad, S., Lingaas Holmen, T., Knudtsen, M., Bygren, L. O., \& Holmen, J. (2012). Patterns of receptive and creative cultural activities and their association with perceived health, anxiety, depression and satisfaction with life among adults: the HUNT study, Norway. Journal of Epidemiology and Community Health, 66(8), 698-703.

Cuypers, K., Krokstad, S., Lingaas-Holmen, T., Skjei-Knudtsen, M., Bygren, L., \& Holmen, J. (2012). Patterns of receptive and creative cultural activities and their association with perceived health, anxiety, depression and satisfaction with life among adults: The HUNT study. Norway Journal of Epidemiology and Community Health, 66(8), 698-703. 
Davey, J. (2007). Older people and transport: coping without a car. Ageing and Society, 27, 49-65. doi:10.1017/S0144686X06005332

Davies, C., Knuiman, M., Wright, P., \& Rosenberg, M. (2014). The art of being healthy: a qualitative study to develop a thematic framework for understanding the relationship between health and the arts. BMJ Open, 4(4), e004790. doi:10.1136/bmjopen-2014-004790

Dodd, J., \& Jones, C. (2014). Mind, body, spirit: How museums impact health and wellbeing. Retrieved from Leicester: https://www2.le.ac.uk/departments/museumstudies/rcmg/publications/mind-body-spirit-report

Dodd, J., Jones, C., Plumb, S., McGhie, H., \& Blazejewski, L. (2018). Unexpected Encounters: How museums nurture living and ageing well. In.

EY. (2016). Health reimagined: a new participatory health paradigm. Retrieved from Australia: https://eysweeney.com.au/Documents/EYHealthReimagined2016.pdf

Fletcher, V. (2013). Museums around the World that Enliven Our Souls: Inclusion through Rich Experience. Curator: The Museum Journal(3), 297.

Fratiglioni, L., Paillard-Borg, S., \& Winbladj, B. (2004). An active and socially integrated lifestyle in late life might protect against dementia. Lancet Neurology, 3(6), 343-353.

Glass, T. A., Leon, C. M., Marottoli, R. A., \& Berkman, L. F. (1999). Population Based Study of Social and Productive Activities as Predictors of Survival among Elderly Americans. BMJ: British Medical Journal, 319, 478 - 483.

Greaves, C. J., \& Farbus, L. (2006). Effects of creative and social activity on the health and wellbeing of socially isolated older people: outcomes from a multi-method observational study. Journal of the Royal Society for the Promotion of Health, 126(3), 134.

Hamblin, K., \& Harper, S. (2016). The UK's ageing population: Challenges and opportunities for museums and galleries. Retrieved from Oxford:

Hawkley, L., \& Cacioppo, J. (2010). Loneliness matters: a theoretical and empirical review of consequences and mechanisms. Annals of Behavioral Medicine, 40(2), 218-227.

Huber, M., Knottnerus, J., Green, L., Van der Horst, H., Jadad, A., Kromhout, D., . . H., S. (2011). How should we define health? BMJ, 343. Retrieved from https://doi.org/10.1136/bmj.d4163

Hudson, K. (1975). A Social History of Museums. London, UK: The Macmillan Press Ltd.

Hughes, C. (2016). Made You Look, Made You Stare: Inspiration from a Museum Road Trip. London: Feilden Clegg Bradley Studios.

Johansson, S. E., Konlaan, B. B., \& Bygren, L. O. (2001). Sustaining habits of attending cultural events and maintenance of health: a longitudinal study. Health Promotion International, 16(3), 229-234.

Kenyon, G., \& Randall, W. (2001). Narrative Gerontology: An Overview. In G. Kenyon, P. Clark, \& B. deVries (Eds.), Narrative Gerontology: theory, research, and practice (pp. 3-18). New York: Springer. 
Konlaan, B. B., Björby, N., Bygren, L. O., Weissglas, G., Karlsson, L. G., \& Widmark, M. (2000).

Attendance at cultural events and physical exercise and health: a randomized controlled study. Public Health, 114(5), 316-319.

Luoh, M. C., \& Herzog, A. R. (2002). Individual Consequences of Volunteer and Paid Work in Old Age: Health and Mortality. Journal of Health and Social Behavior, 43(4), 490-509. doi:10.2307/3090239

McAuley, E., Blissmer, B., Marquez, D. X., Jerome, G. J., Kramer, A. F., \& Katula, J. (2000). Social relations, physical activity, and well-being in older adults. Preventive Medicine, 31(5), 608617.

Menec, V. H. (2003). The Relation Between Everyday Activities and Successful Aging: A 6-year Longitudinal Study. The Journals of Gerontology, Series B, 58(2), S74-S82. doi:10.1093/geronb/58.2.S74

Nolen-Hoeksema, S., \& Ahrens, C. (2002). Age differences and similarities in the correlates of depressive symptoms. Psychology and Aging, 17(1), 116-124.

O'Neill, M. (2010). Cultural attendance and public mental health - from research to practice. Journal of Public Mental Health, 9(4), 22-29. doi:10.5042/jpmh.2010.0700

Owen, T. (2001). The high cost of isolation. Working with Older People: Community Care Policy \& Practice, 5(1), 21-23.

Ruiz, J. (2004). A Literature Review Of The Evidence Base For Culture, The Arts And Sport Policy. Edinburgh: Scottish Government. Retrieved from http://www.scotland.gov.uk/Publications/2004/08/19784/41510.

Schwanen, T., Lucas, K., Akyelken, N., Cisternas Solsona, D., Carrasco, J., \& Neutens, T. (2015). Rethinking the links between social exclusion and transport disadvantage through the lens of social capital. Transport Research Part A: Policy and Practice, 74, 123-135.

Sharpe, E., \& Miller, M. (2015). Artifact Stories: Making memories matter. In H. Robertson (Ed.), The Caring Museum (pp. 88-97). UK: Museums Etc Ltd.

Staricoff, R. L. (2004). Can the Arts Have a Positive Effect on Health? A review of the medical literature: : Arts Council of England.

Steptoe, A., Owen, N., Kunz-Ebrecht, S., \& Brydon, L. (2004). Loneliness and neuroendocrine, cardiovascular, and inflammatory stress responses in middle-aged men and women. Psychoneuroendicrinology, 29(5), 593-611.

Team, T. M. R. (2010). Fair Society, Healthy Lives: Strategic Review of Health Inequalities in England post-2010. London: Marmot Review Team.

Temple, J., Rice, J., McDonald, P. (2017a). Mature age labour force participation and the life cycle deficit in Australia: 1981-82 to 2009-10. The Journal of the Economics of Ageing 10(c): 2133. 
Temple, J., McDonald, P., Rice, J. (2017b). Net assets available at age of death in Australia: An extension of the Naitonal Transfer Accounts Methodology. Population Review 56(2).

UCL, \& WHO. (2014). Review of the Social Determinants of Health and the Health Divide in the WHO European Region. Retrieved from Copenhagen:

http://www.euro.who.int/_data/assets/pdf file/0004/251878/Review-of-social-determinantsand-the-health-divide-in-the-WHO-European-Region-FINAL-REPORT.pdf

Victor, C. R., \& Scharf, T. (2005). Social Isolation and Loneliness. In A. Walker (Ed.), Understanding Quality of Life in Old Age (pp. 100-116): Open University Press.

Whitehouse, P. (2015). Preface. In H. Robertson (Ed.), The Caring Museum: new models of engagement with ageing (pp. 11-22). Edinburgh and Boston: MuseumsEtc.

Wilkinson, A. V., Waters, A. J., Bygren, L. O., \& Tarlov, A. R. (2007). Are variations in rates of attending cultural activities associated with population health in the United States? $B M C$ Public Health, 7, 226-226.

Winter, N. (2008). SVR: Stata module to compute estimates with survey replication based standard errors. In.

Wolfer, K. (1985). Introduction to Variance Estimation. New York: Springer-Verlag. 


\section{University Library}

\section{- M M N E R VA A gateway to Melbourne's research publications}

Minerva Access is the Institutional Repository of The University of Melbourne

Author/s:

Temple, J;Gan, L

Title:

Habits of a Lifetime: Museum Visitation Amongst Older Australians

Date:

2020-09-30

Citation:

Temple, J. \& Gan, L. (2020). Habits of a Lifetime: Museum Visitation Amongst

Older Australians. JOURNAL OF POPULATION AGEING, https://doi.org/10.1007/ s12062-020-09304-4.

Persistent Link:

http://hdl.handle.net/11343/253849 